\title{
Evaluated Nuclear Structure Data File and Related Products
}

\author{
Jagdish K. Tuli \\ National Nuclear Data Center, Brookhaven National Laboratory, Upton, NY 11973-5000, USA
}

\begin{abstract}
The Evaluated Nuclear Structure Data File (ENSDF) is a leading resource for the experimental nuclear data. It is maintained and distributed by the National Nuclear Data Center, Brookhaven National Laboratory. The file is mainly contributed to by an international network of evaluators under the auspice of the International Atomic Energy Agency. The ENSDF is updated, generally by mass number, i.e., evaluating together all isobars for a given mass number. If, however, experimental activity in an isobaric chain is limited to a particular nuclide then only that nuclide is updated. The evaluations are published in the journal Nuclear Data Sheets, Academic Press, a division of Elsevier.
\end{abstract}

\section{INTRODUCTION}

The Evaluated Nuclear Structure Data File (ENSDF) contains evaluated nuclear structure and decay information for practically all known, over 2900 , nuclides. It is maintained by the National Nuclear Data Center at Brookhaven National Laboratory on behalf of the International Nuclear Structure and Decay Data Network (NSDD). The NSDD is coordinated by the International Atomic Energy Agency (IAEA), Vienna. Current membership of the network includes scientists from Australia, Argentina, Belgium, Brazil, Bulgaria, Canada, China, France, India, Japan, Kuwait, Russia, and the United States.

The file is updated on a continuous basis. New evaluations are published in Nuclear Data Sheets. ${ }^{1}$

\section{File Structure}

The file is organized (fig. 1) by mass number of the resulting/daughter nuclide, and within a mass number it is organized by increasing $Z$ value. For each nuclide, (i.e., for a $Z$ value) the information is given in data sets with a separate data set for each kind of experiment by which a nuclide has been studied. Several experiments leading to similar information may be combined under

'Elsevier Inc., San Diego, CA. one data set. There is a summary data set called the Adopted Levels, Gammas data set for each nuclide which summarizes the level and gamma-ray properties for that nuclide. If there is only one experiment from which all the information for a nuclide is derived, the corresponding data set is also regarded as the adopted data set for the nuclide. There are two data sets for each mass number (A-chain), namely the Comments and Reference data sets, which summarize the evaluation and give translations for the key numbers used in the A-chain, respectively. For complete format details of ENSDF see Ref. [1].

\section{Evaluation Policy}

The evaluation philosophy for ENSDF and the Nuclear Data Sheets, is to present the best data available from each type of experiments in a welldocumented manner. The emphasis in ENSDF is on the nuclear structure and decay properties obtained from the experimental evidence or well-founded systematics and theory. This approach results in an excellent general-purpose file useful to both the basic and the applied scientist. No attempt is made to interpolate or extrapolate results to obtain properties which have not been observed. In particular, considerable emphasis is placed on assigning $J^{\pi}$ values which are based upon well established "strong" rules. Those values not meeting the criteria and based upon one or more less established criteria (so called "weak" rules) are placed in parentheses. The ENSDF 


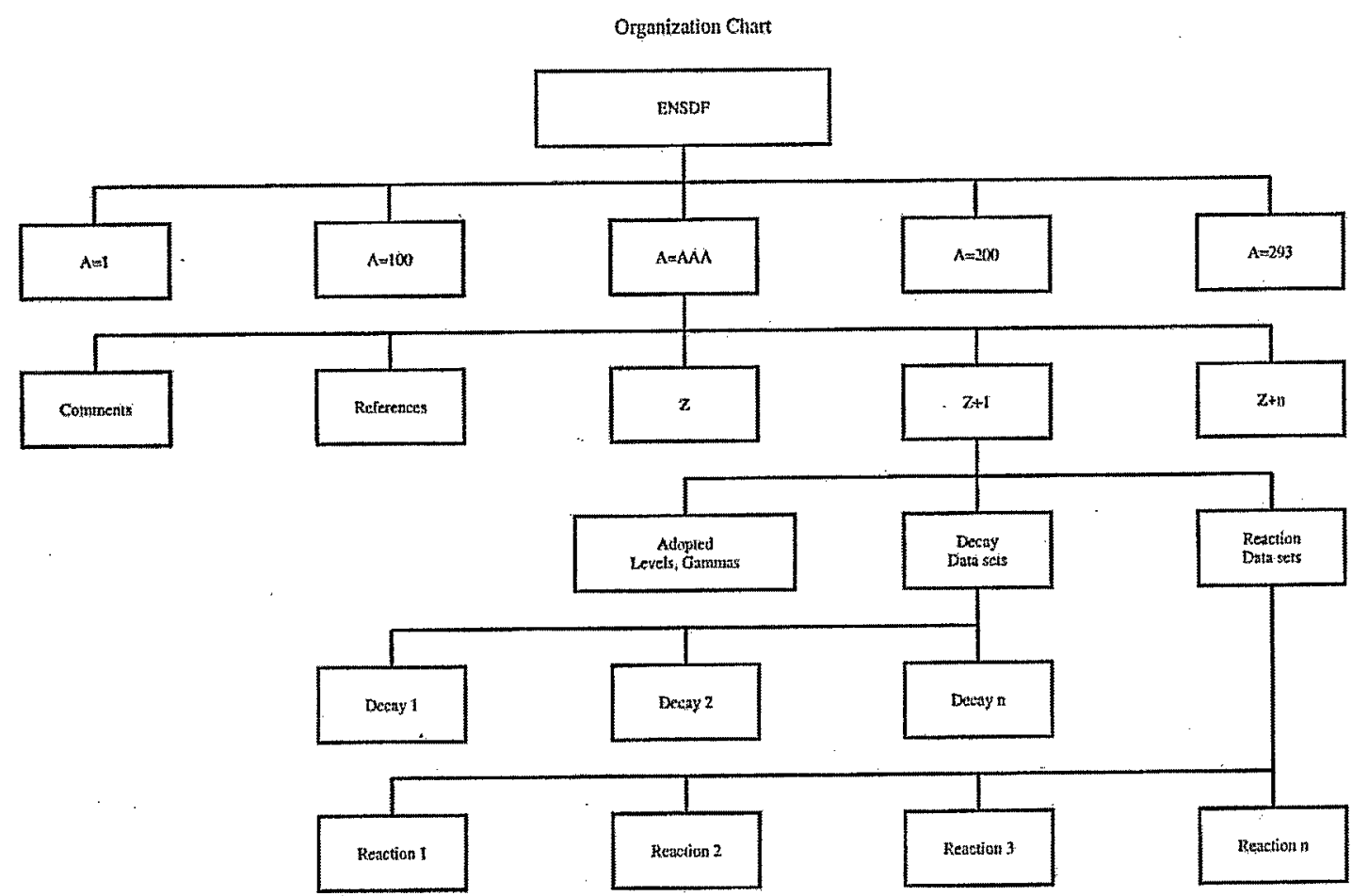

FIGURE 1. ENSDF Organization Chart

evaluators often depend on specialized "horizontal" evaluations available in literature. For example, the mass recommendations of Audi, Wapstra, and Thibault [2] and moments from Raghavan's [3] or Stone's [4] compilations are generally quoted and any divergence from their values are noted.

All evaluations are run through the same set of analysis and checking codes to produce uniform results. For example, all conversion coefficients given in the file are as calculated from the Hager and Seltzer tables [5] supplemented with Dragoun, Plajner, and Schmutzler [6] and Band, Trzhaskovskaya, and Listengarten [7] values. It is proposed to replace these tables by Band, Trzhaskovskaya, Nestor,Jr., Tikkanen, and Raman [8] calculations in near future. All reduced transition probabilities are calculated using the adopted half-lives, branching ratios, and the conversion coefficients.
The file is continuously updated with publication of evaluations as full mass chains every few years. In between the publications, new data are included in the file which can be accessed through the web, www.nnde.bnl.gov. The derivative databases, NUDAT, MIRD, and Nuclear Wallet Cards, which provide the information from ENSDF in a userfriendly interactive form, are also available through the NNDC portal.

\section{Publications}

The evaluations from ENSDF are generally published as Nuclear Data Sheets. ENSDF was also the main source of the following publications: Table of Radioactive Isotopes [9], Table of Isotopes, $8^{\text {th }}$ edition [10], Nuclear Wallet Cards [11], Nuclear Wallet Cards for Radioactive Nuclides [12] 

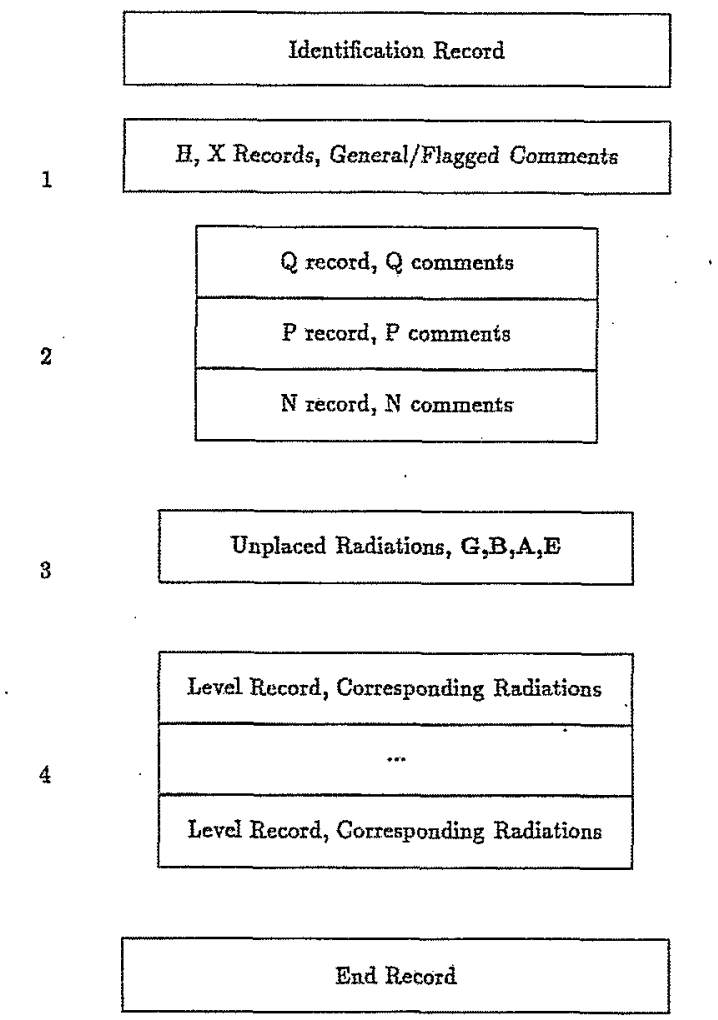

FIGURE 2. Data set structure

\section{Summary}

The Evaluated Nuclear Structure Data File (ENSDF) is the product of a very successful and continuing international collaboration effort spanning over three decades. ENSDF is one of the major databases which constitute the extremely popular NNDC web portal. The databases, NUDAT, MIRD, and Nuclear Wallet Cards on the portal provide the information from ENSDF in a user-friendly, interactive form.

\section{Acknowledement}

This work is supported by the Department of Energy, Office of Nuclear Physics, Office of Science, US Department of Energy, under contract no. DE-AC0298CH10886.

\section{REFERENCES}

1. J.K. Tuli, Evaluated Nuclear Structure Data File - A Manual for Preparation of Data Sets, Rept. BNL-NCS51655-01/02-Rev (2001).

2. G. Audi, A.H. Wapstra, and C. Thibault Nucl. Phys. A729, 337 (2003)

3. P. Raghavan, At. Nucl. Data Tables 42, 189 (1989).

4. N. Stone, priv. comm., NNDC web site.

5. R.S. Hager and E.C. Seltzer, Nucl. Data A4, 1 (1968).

6. O. Dragoun, Z. Plajner, and F. Schumutzler, Nucl. Data Tables A9, 119 (1971)

7. I.M. Band, M.B. Trzhaskovskaya, and M.A. Listengarten, At. Nucl. Data Tables 18, 433 (1976).

8.I.M.Band,M.B..Trzhaskovskaya,C.W.Nestor,Jr.,,,P.O. Tikkanen, S.Raman, At.Data Nucl.Data Tables 81, 1 (2002)

9. E. Browne, R.F. Firestine, V.S. Shirley, Table of Radioactive Isotopes, John Wiley (1986)

10. R.F. Firestone, V.S. Shirley, C.M. Baglin, S.Y.F. Chu, J. Zipkin, Table of Isotopes, $8^{\text {th }}$ edition, John Wiley (1996)

11. J.K. Tuli, Nuclear Wallet Cards, $6^{\text {th }}$ edition ( 2000

12. J.K. Tuli, Nuclear Wallet Cards for Radioactive Nuclides 


\section{DISCLAIMER}

This report was prepared as an account of work sponsored by an agency of the United States Government. Neither the United States Government nor any agency thereof, nor any of their employees, nor any of their contractors, subcontractors, or their employees, makes any warranty, express or implied, or assumes any legal liability or responsibility for the accuracy, completeness, or any third party's use or the results of such use of any information, apparatus, product, or process disclosed, or represents that its use would not infringe privately owned rights. Reference herein to any specific commercial product, process, or service by trade name, trademark, manufacturer, or otherwise, does not necessarily constitute or imply its endorsement, recommendation, or favoring by the United States Government or any agency thereof or its contractors or subcontractors. The views and opinions of authors expressed herein do not necessarily state or reflect those of the United States Government or any agency thereof. 